\title{
A Study on the Running Safety of F26 Turnout and Vehicle Model
}

\author{
Sung Jong Kim*, Beom-Gyu Eom** and Hi Sung Lee ${ }^{\dagger}$
}

\begin{abstract}
When a vehicle passes through turnout, it is required to minimize the changes of lateral force for running safety of vehicle. Therefore, it is necessary to analyze interaction between the vehicle and the turnout in order to estimate the lateral force and the derailment coefficient on the turnout. In this paper, analysis model of the vehicle and turnout are established and analysis is carried out when the vehicle passes through turnout in order to improve running safety of the vehicle on turnout. To verify the vehicle and turnout analysis model, the contact points between wheel and rail and the influence of changing cradle and tongue rail are also discussed.
\end{abstract}

Keywords : Running safety, Turnout, Derailment coefficient, Lateral force

\section{Introduction}

It is required to minimize the changes of lateral force in the high speed rail when a high speed railway vehicle passes through turnout. But, existing turnout design considered turnout as a mass and only kinematical analysis was carried out, therefore the response of wheel and turnout was distorted. For the design and evaluation of turnout, dynamic analysis is required. That is, to predict the lateral force and lateral acceleration when a vehicle passes turnout, dynamic analysis considering interaction between vehicle and turnout is essential.

Chung et al. predicted dynamic characteristic change of vehicle passing through \#65 high speed turnout, and Han et al. developed dynamic analysis program for contact characteristic between wheel and rail. In this paper, analysis model of the vehicle and turnout are established and analysis is carried out when the vehicle passes through turnout in order to improve running safety of the vehicle on turnout. And to verify the vehicle and turnout analysis model, the contact points

\footnotetext{
$\uparrow$ Corresponding author: Professor, Graduate School of Railroad, Seoul National University of Science \& Technology

E-mail : hslee@seoultech.ac.kr

* Director, Transportation R\&D Department/Railroad Division, KICTEP

${ }^{* *}$ Doctor's candidate, Graduate School of Railroad. Seoul National University of Science \& Technology
}

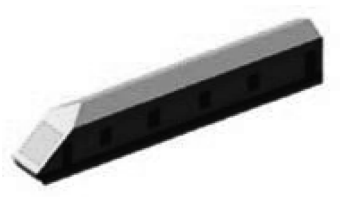

(a) Carbody

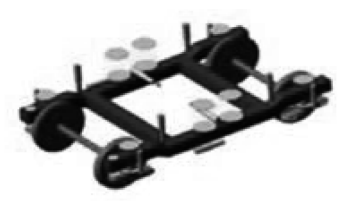

(b) Bogie

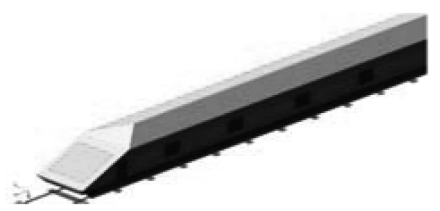

(c) Full assembly of vehicle

Fig. 1 Vehicle analysis model

between wheel and rail were analyzed, and finally the influence of changing cradle and tongue rail on the running safety are also investigated.

\section{Analysis Model}

\subsection{Vehicle model}

In this study, VI-Rail the railway dynamic characteristic analysis package was used. The vehicle model was built for a KTX power car as shown in Fig. 1.

The characteristics of KTX power car suspension component used for vehicle model are shown in Table 1. 
Table 1. Characteristics of KTX Power Car Suspension Component

\begin{tabular}{|c|c|c|c|c|c|c|c|}
\hline \multirow{2}{*}{ Suspension component } & \multicolumn{6}{|c|}{ Characteristics } & \multirow{2}{*}{ Remarks (Unit) } \\
\hline & $\mathrm{F}_{\mathrm{X}}$ & $\mathrm{F}_{\mathrm{y}}$ & $\mathrm{F}_{\mathrm{z}}$ & $\mathrm{T}_{\mathrm{x}}$ & $\mathrm{T}_{\mathrm{y}}$ & $\mathrm{T}_{\mathrm{z}}$ & \\
\hline Double coil spring & 0.5813 & 0.5813 & 0.752 & 0.1 & 0.1 & 0.1 & $\mathrm{MN} / \mathrm{m}$ \\
\hline Guide spring & 20.0 & 4.5 & 0.25 & 0.044 & 0.03 & 0.473 & $\begin{array}{c}\mathrm{MN} / \mathrm{m} \\
\mathrm{MNm} / \mathrm{rad}\end{array}$ \\
\hline 1st vertical oil damper & & & 0.01 & & & & $\mathrm{MN} / \mathrm{m}$ \\
\hline Coil spring & 0.15 & 0.15 & 0.634 & 0.1 & 0.1 & 0.1 & $\begin{array}{c}\mathrm{MN} / \mathrm{m} \\
\mathrm{MNm} / \mathrm{rad}\end{array}$ \\
\hline 2nd vertical oil damper & & & 0.02 & & & & $\mathrm{MNs} / \mathrm{m}$ \\
\hline Lateral oil damper & & 0.01 & & & & & $\mathrm{MNs} / \mathrm{m}$ \\
\hline \multirow{2}{*}{ Anti yaw oil damper } & 0.0 & 0.0026 & 0.01 & 0.02 & 0.3 & & $\mathrm{~m} / \mathrm{s}$ \\
\hline & 0.0 & 11.0 & 11.6 & 12.0 & 19.0 & & $\mathrm{KN}$ \\
\hline Pivot joint & 10.29 & & & & & & $\mathrm{MN} / \mathrm{m}$ \\
\hline \multirow{2}{*}{ Side bump stop } & -70.0 & -65.0 & -60.0 & -55.0 & -45.0 & 0.0 & $\mathrm{~mm}$ \\
\hline & -45.0 & -13.0 & -5.0 & -2.0 & 0.0 & 0.0 & $\mathrm{KN}$ \\
\hline
\end{tabular}

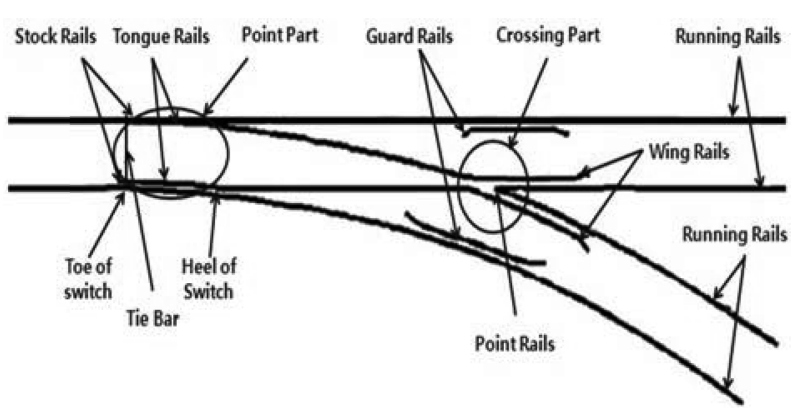

Fig. 2 Components of a turnout

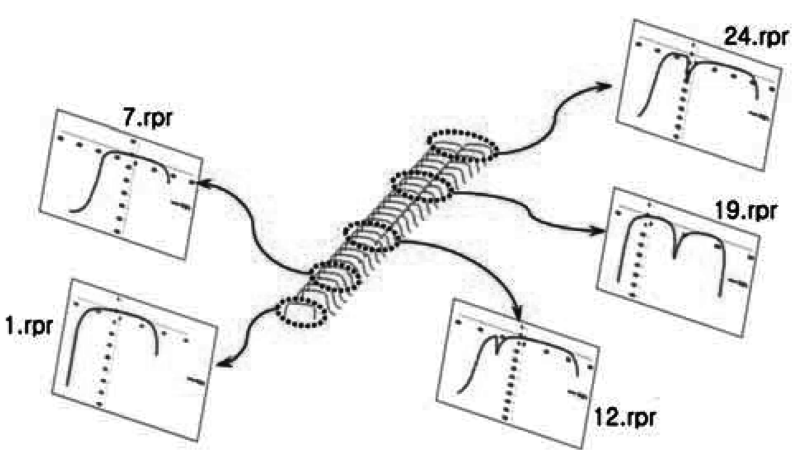

Fig. 3 Section profile of the outer rail

\subsection{F26 turnout model}

Turnouts are comprised of a point part, lead part and crossing part. The point part is entering section, which is starting point where the wheels transferred from stock rail to switch rail. The point part consists of stock rail and switch rail(tongue rail). The stock rail has constant cross-section of UIC 60 rail and the switch rail has basi-

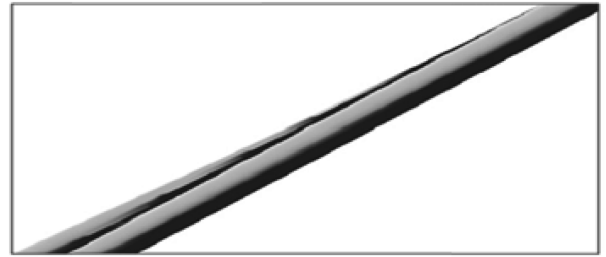

(a) Point part

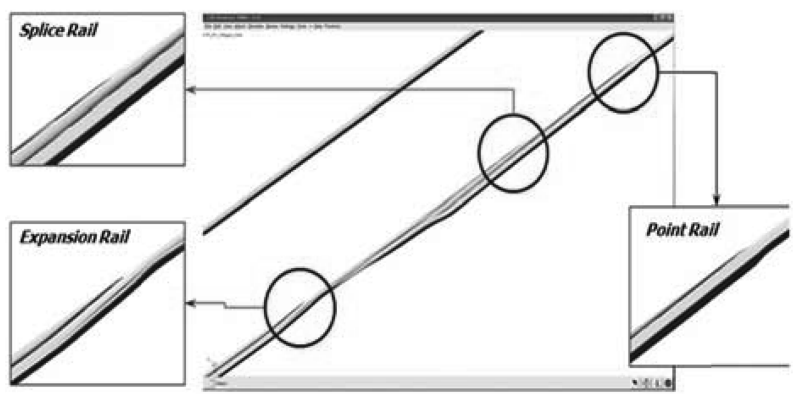

(b) Crossing part

Fig. 4 Dynamic analysis 3D model of F26 turnout

cally UIC $60 \mathrm{D}$ rail cross-section but varies along the longitudinal direction by cutting work. The lead part which connects the point and the crossing parts has UIC60D rail cross-section and its cross-section shape changes to that of UIC60 rail. At the crossing part, the divided rail from the point part intersects with opposite stock rail. It consists of cradle, point rail and guard rail etc. The cradle is the biggest single component in the crossing part, the point rail decides the travelling direction of the wheel and the guard rail supports the lateral force in the crossing part. Fig. 2 shows the components 
of a turnout.

The cross-sections of outer rail where contact between wheel and rail take place are extracted from 2D drawings of the F26 turnout and arranged along longitudinal direction as shown in Fig. 3. Total 20 cross-sections for point part and 35 cross-sections for crossing part are used.

Dynamic analysis model of the turnout was built in 3D by forming surfaces from the cross-sections of the outer rail as shown in Fig. 4. It is rigid body model and 3D model for point part and crossing part is shown in Fig. 4(a) and 4(b) respectively.

\section{Dynamic Analysis}

\subsection{Running safety analysis of F26 turnout}

The contact points between wheel and rail are derived from the dynamic analysis result when the vehicle travels on F26 turnout for the verification of vehicle and turnout model and they are shown in Fig. 5. We can find the points of contact between wheel and rail and directions of reaction forces with running time. The first contact between switch rail and wheel happened at travelling time of $0.62 \mathrm{sec}$ and travelling distance of $34.3 \mathrm{~m}$, when the dividedness started. At the $1.81 \mathrm{sec}$., $63.9 \mathrm{~m}$, the wheel passed the point part, and the wheel started contact with point rail of crossing part at 3.48 sec., $105.7 \mathrm{~m}$. At the $3.64 \mathrm{sec}$., $109.5 \mathrm{~m}$, the wheel

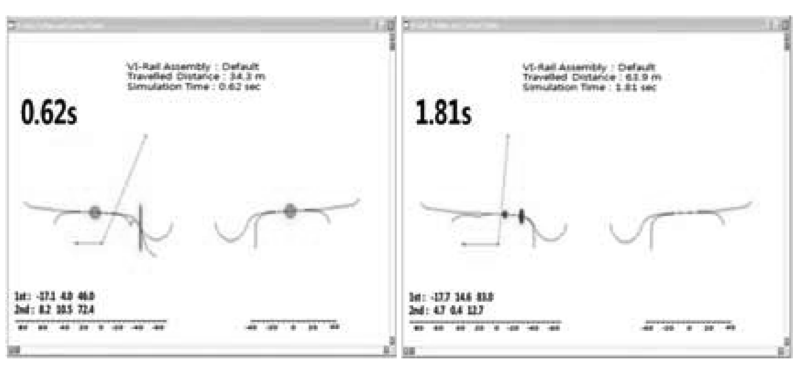

(a) $0.62 \mathrm{sec}$.

(b) $1.81 \mathrm{sec}$.

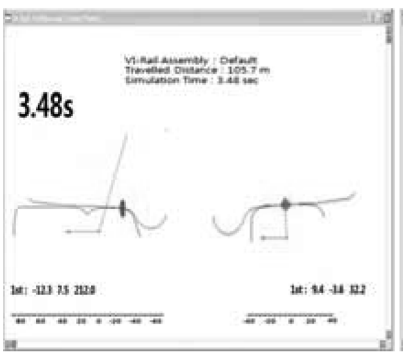

(c) $3.48 \mathrm{sec}$.

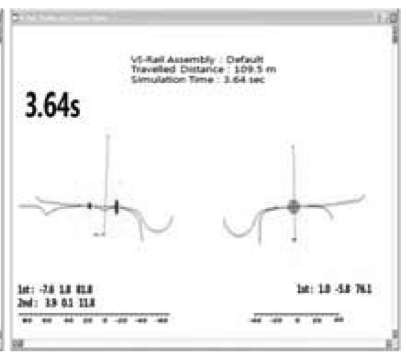

(d) $3.64 \mathrm{sec}$.
Fig. 5 Contact points between wheel and rail with time made contact with splice rail.

Fig 6 shows the running safety analysis results of high speed railway vehicle passing F26 turnout, and the results were tabulated in Table 2.

Looking over the analysis results revealed that vertical force had increased about $86 \%$ from initial state, and inter-

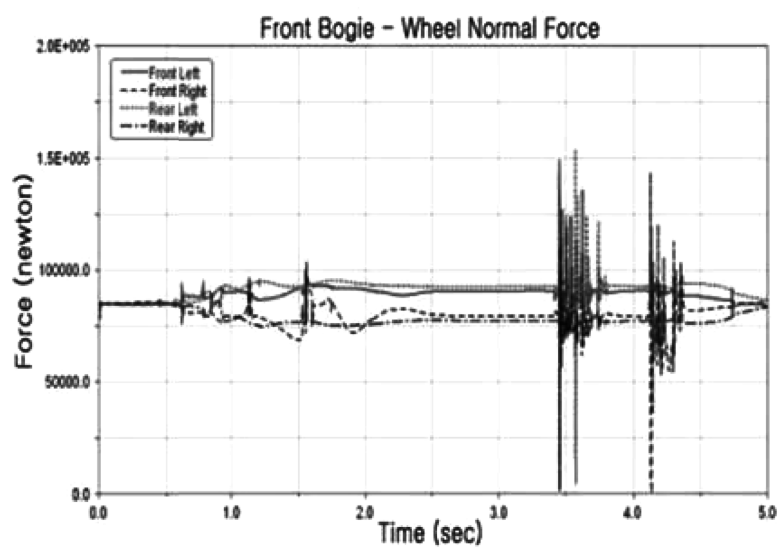

(a) Vertical force

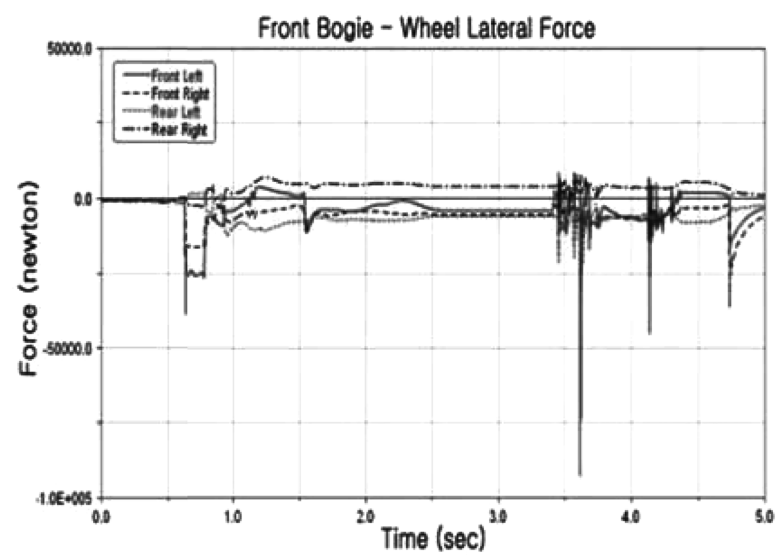

(b) Lateral force

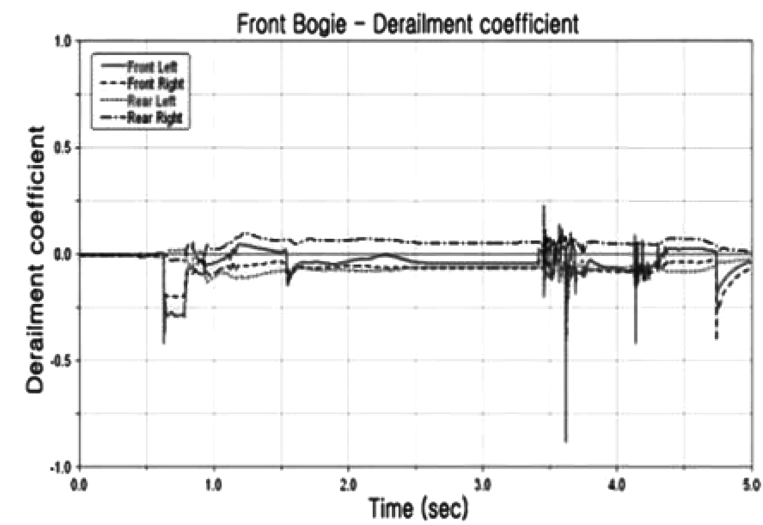

(c) Derailment coefficient

Fig. 6 Analysis results of F26 turnout 
Table 2. Analysis Results of F26 Turnout

\begin{tabular}{|c|c|c|c|c|c|c|}
\hline & Parameters & & Vertical force $[\mathrm{N}]$ & Lateral force $[\mathrm{N}]$ & $\begin{array}{l}\text { Derailment } \\
\text { coefficient }\end{array}$ & Remarks \\
\hline \multirow{4}{*}{ Front bogie } & \multirow{2}{*}{$1 \mathrm{st}$} & $\mathrm{LH}$ & $1.49 \mathrm{E}+05$ & $-9.24 \mathrm{E}+04$ & -0.88 & \multirow{8}{*}{$\begin{array}{c}\text { Straight line : } \\
\text { vertical force } \\
84,748 \mathrm{~N}\end{array}$} \\
\hline & & RH & $1.43 \mathrm{E}+05$ & $-3.63 \mathrm{E}+04$ & -0.41 & \\
\hline & \multirow{2}{*}{2 nd } & LH & $1.54 \mathrm{E}+05$ & $-2.19 \mathrm{E}+04$ & -0.21 & \\
\hline & & RH & $1.36 \mathrm{E}+05$ & $8.96 \mathrm{E}+03$ & 0.22 & \\
\hline \multirow{4}{*}{ Rear bogie } & \multirow{2}{*}{$1 \mathrm{st}$} & LH & $1.58 \mathrm{E}+05$ & $-8.08 \mathrm{E}+04$ & -0.54 & \\
\hline & & RH & $1.40 \mathrm{E}+05$ & $-2.21 \mathrm{E}+04$ & -0.29 & \\
\hline & \multirow{2}{*}{ 2nd } & LH & $1.50 \mathrm{E}+05$ & $-2.39 \mathrm{E}+04$ & -0.21 & \\
\hline & & RH & $1.39 \mathrm{E}+05$ & $1.02 \mathrm{E}+04$ & 0.18 & \\
\hline
\end{tabular}

Table 3. Analysis Results of F26 Turnout by Variation of Switch Rail

\begin{tabular}{cccccc}
\hline \multirow{2}{*}{ Parameters } & \multicolumn{5}{c}{ Switch rail (tongue rail) } \\
\cline { 2 - 6 } & Vertical force $[\mathrm{N}]$ & Lateral force $[\mathrm{N}]$ & $\begin{array}{c}\text { Lateral } \\
\text { acceleration[m/s2] }\end{array}$ & $\begin{array}{c}\text { Vertical } \\
\text { acceleration[m/s2] }\end{array}$ & $\begin{array}{c}\text { Derailment } \\
\text { coefficient }\end{array}$ \\
\hline Origin & 132,800 & $-62,592$ & 24.035 & 52.024 & -0.8109 \\
\hline Case $1(-2 \mathrm{~m})$ & 132,830 & $-63,106$ & 24.23 & 52.501 & -0.8159 \\
\hline Case $2(+2 \mathrm{~m})$ & 132,780 & $-62,099$ & 23.843 & 51.569 & -0.8062 \\
\hline
\end{tabular}

nal wheel of the 2nd axle suffered higher force than external wheel of the 1st axle. Lateral force had sign of minus(-) as the vehicle ran on right curve and had very high value at the cradle. Derailment coefficient of external wheel of the 1 st axle slightly exceeded 0.8 around the cradle, but it was transient result and there was nothing wrong with running safety.

\subsection{Cross-section variation of switch rail (tongue rail)}

To investigate the effect of cross-section variation of switch rail, the length of switch rail was changed from $-2 \mathrm{~m}$ to $2 \mathrm{~m}$ compared to original length. Curvature and crosssection shape change was not considered, but linear variation of the length was taken into account. Case 1 is analysis condition of $2 \mathrm{~m}$ decrease, Case 2 is condition of $2 \mathrm{~m}$ increase than original switch rail length.

Fig. 7 shows the running safety analysis results of high speed railway vehicle passing F26 turnout according to cross-section variation of switch rail, and the results were tabulated in Table 3.

Looking over the analysis results revealed that vertical force, lateral force and lateral acceleration had similarly decreased in Case 2 than original case. As the vertical acceleration and derailment coefficient decreased about $0.9 \%$ and $0.6 \%$ each, the effect of switch rail variation was slight.

Although the amount was small, the force and the accel-

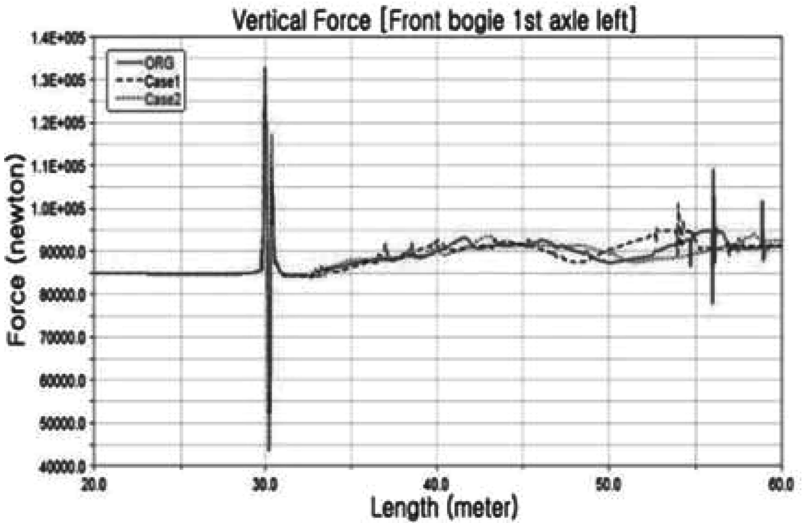

(a) Vertical force

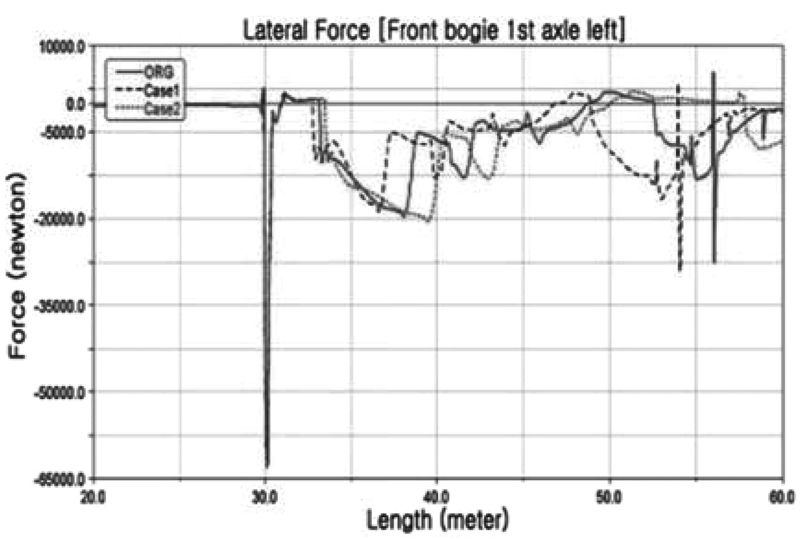

(b) Lateral force

Fig. 7 Analysis results of F26 turnout by variation of switch rail 


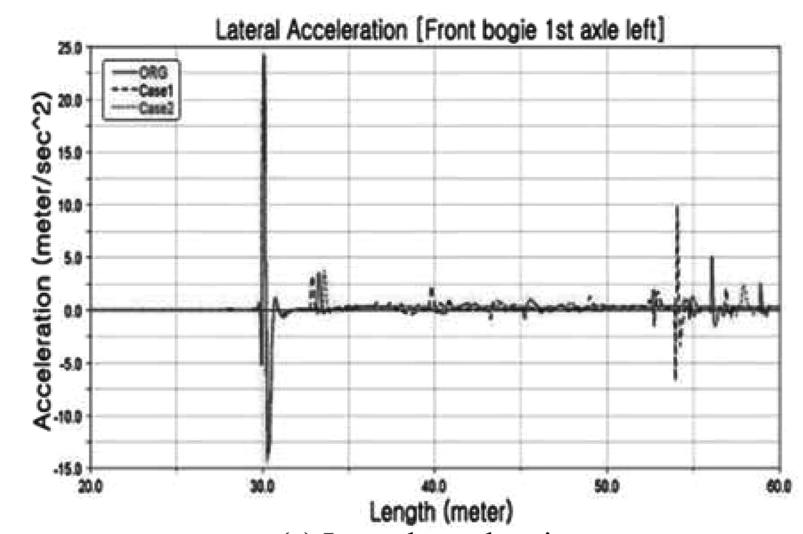

(c) Lateral acceleration

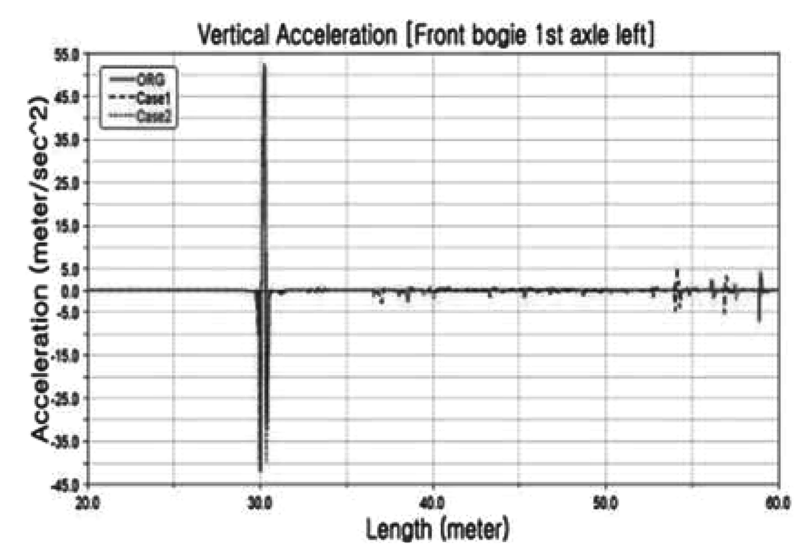

(d) Vertical acceleration

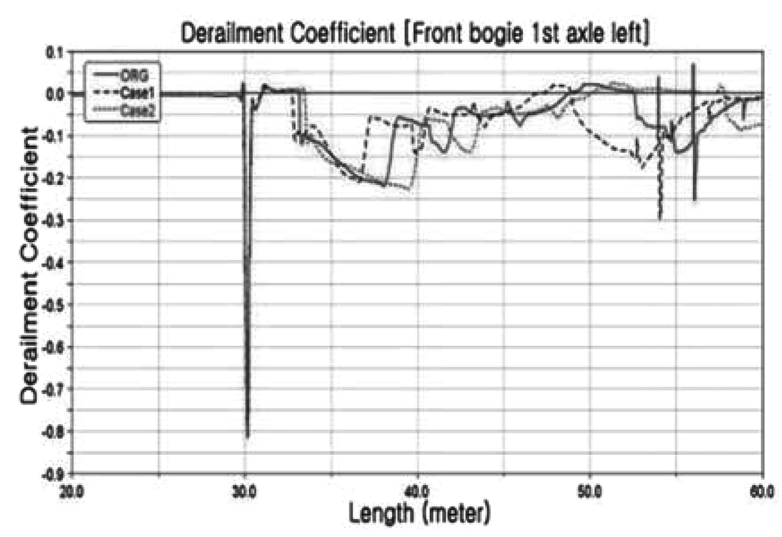

(e) Derailment coefficient

Fig. 7 Continued eration tended to decrease in general as the length of switch rail increases. Therefore, the increase in length of switch rail is advantageous to running safety so far as the turnout system permits.

\subsection{Cross-section variation of cradle}

Cradle has more complicated shape and cross-section variation is severer than switch rail. To investigate the effect of cross-section variation of cradle, the length of cradle was changed from $-2 \mathrm{~m}$ to $2 \mathrm{~m}$ compared to original length. Without considering cross-section change of each component, linear variation of the total length was

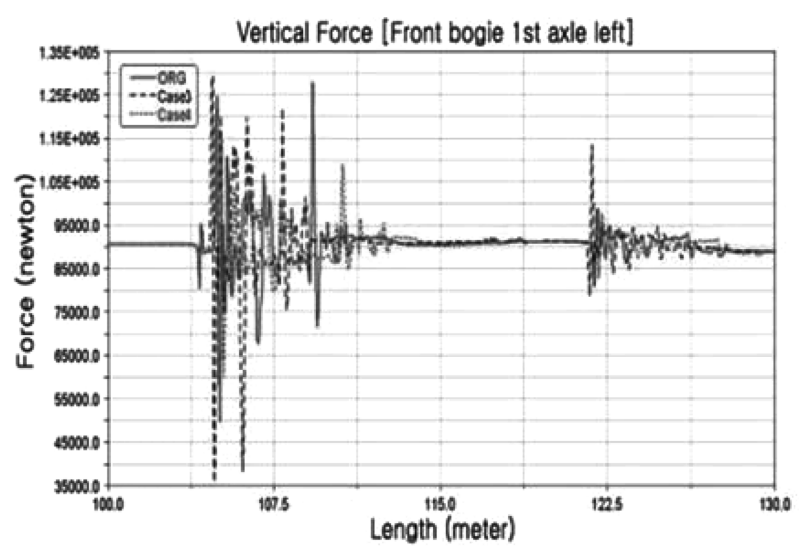

(a) Vertical force

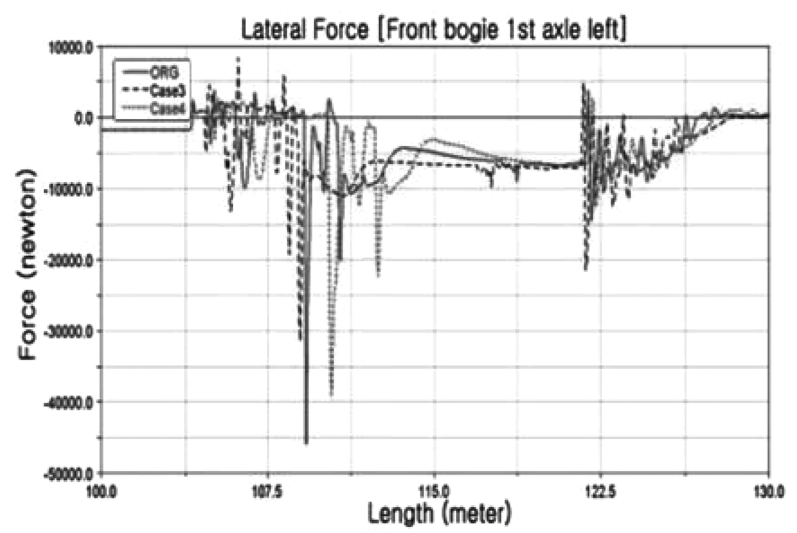

(b) Lateral force

Fig. 8 Analysis results of F26 turnout by variation of cradle

Table 4. Analysis Results of F26 Turnout by Variation of Cradle

\begin{tabular}{ccccc}
\hline & & \multicolumn{3}{c}{ Cradle } \\
\cline { 2 - 5 } Parameters & Vertical force [N] & Lateral force [N] & $\begin{array}{c}\text { Lateral } \\
\text { acceleration[m/s2] }\end{array}$ & $\begin{array}{c}\text { Vertical } \\
\text { acceleration[m/s2] }\end{array}$ \\
\hline ORG & 128,000 & $-45,895$ & 21.512 & 47.224 \\
Case 3(-2 m) & 129,000 & $-31,442$ & 14.833 & 68.701 \\
\hline Case 4(+2 m) & 117,000 & $-39,307$ & 13.711 & 35.071 \\
\hline
\end{tabular}




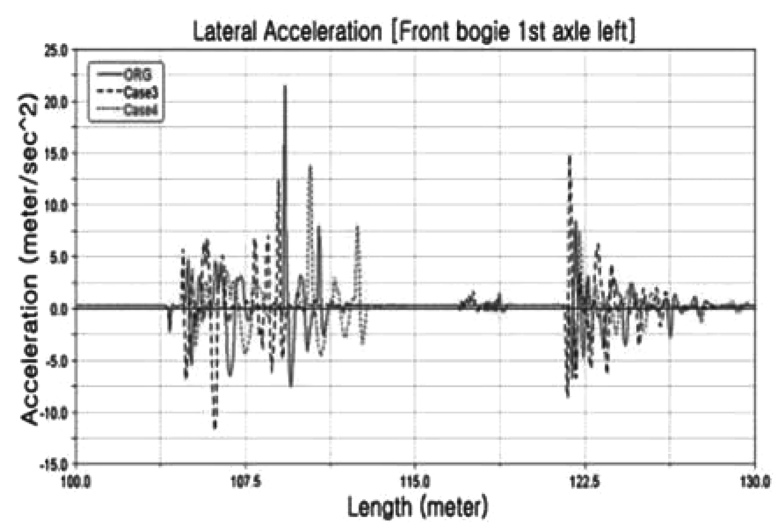

(c) Lateral acceleration

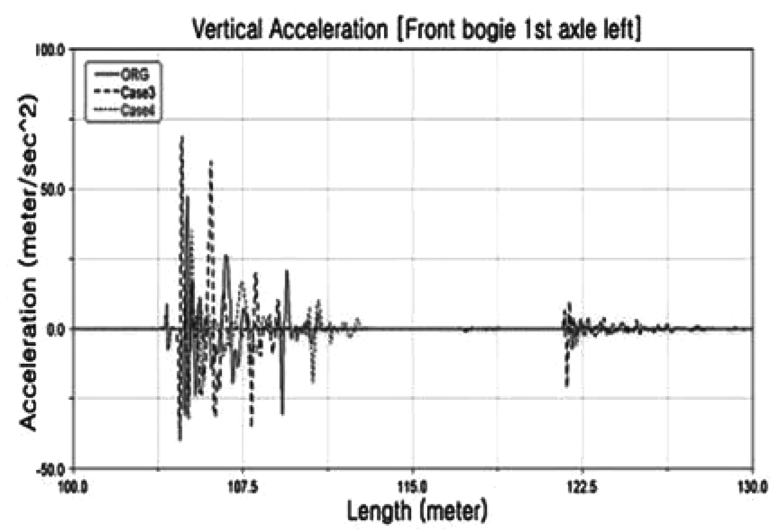

(d) Vertical acceleration

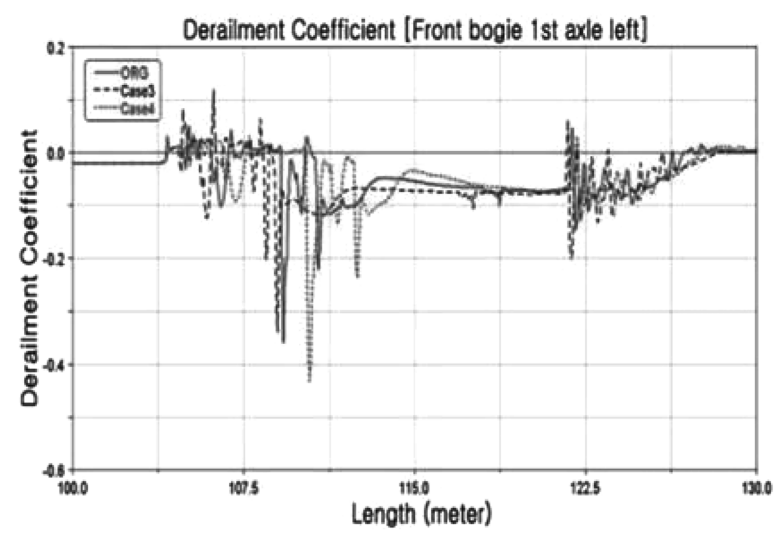

(e) Derailment coefficient

Fig. 8 Continued

taken into account. The length of alteration section is $10.6 \mathrm{~m}$, Case 3 is analysis condition of $2 \mathrm{~m}$ decrease, Case 4 is condition of $2 \mathrm{~m}$ increase than original cradle length.

Fig. 8 shows the running safety analysis results of high speed railway vehicle passing F26 turnout according to cross-section variation of cradle, and the results were tabulated in Table 4.
Looking over the analysis results revealed that vertical force decreased in Case 4, lateral force and lateral acceleration decreased in both cases, on the other hand, vertical acceleration increased in Case 3 than original case. And the derailment coefficient decreased in Case 3.

It is assumed the reason of such inconsistent results is because although the shape of each component and connections between components are important for cradle, only total length variation of cradle was considered in the analysis. But it was found that the less variation of crosssection for length the more improvement of dynamic characteristics could be possible.

\section{Conclusion}

In this paper, analysis model of the vehicle and turnout are established and analysis is carried out when the vehicle passes through turnout in order to improve running safety of the vehicle on turnout. The contact points between wheel and rail are derived from the dynamic analysis for the verification of vehicle and turnout model. The influence of changing cross-section of cradle and switch rail(tongue rail) are also discussed. From the above results, the conclusion was drawn as follows.

1. From the running safety analysis results of high speed railway vehicle on F26 turnout, it is revealed that vertical force had increased about $86 \%$ from initial state, and internal wheel of the 2nd axle suffered higher force than external wheel of the 1st axle. Derailment coefficient of external wheel of the 1st axle slightly exceeded 0.8 around the cradle, but it was transient result and there was nothing wrong with running safety.

2. From the analysis results of F26 turnout by variation of switch rail, it is revealed that the effect of switch rail variation was slight. Although the amount was small, the force and the acceleration tended to decrease in general as the length of switch rail increases. Therefore, the increase in length of switch rail is advantageous to running safety so far as the turnout system permits.

3. From the analysis results of F26 turnout by variation of cradle, it is revealed that although analysis results were not consistent, the less variation of cross-section for length the more improvement of dynamic characteristics could be possible.

4. For the improvement of dynamic characteristic of turnout, it is necessary to find improvement plan of cross-section of turnout components along with the design constraints such as strength and geometric line form. 


\section{References}

1. Kassa Elias, Andersson Clas and Nielsen Jens (2006). "Simulation of dynamic interaction between train and railway turnout", Vehicle System Dynamics, Vol. 44, No. 3, pp. $247-$ 258.

2. C Andersson and T Dahlberg (1998). "Wheel/rail impacts at a railway turnout crossing", Proceedings of the Institution of Mechanical Engineers, pp. 123-134.

3. W Ping, C Rong and C Xiaoping (2009). "Wheel/rail relationship optimization of switch zone in high-speed railway turnout", Proceedings of the Second International Conference on Transportation Engineering.
4. Chung, W. J., Shin, J. R., Yang, S. C. and Kim, N. P. (2000). "Study on the dynamic characteristics of rolling stocks passing on the high speed turnout system", Spring Conference of the Korean Society for Railway, pp. 226-233.

5. Han, H. S., Kim, M. C., Hur, H. M. and Hur, Y. C. (2006). "Analysis of wheel/rail contact characteristics on a turnout", Autumn Conference of the Korean Society for Railway, pp. 14-19.

6. J. Rainer Oswald (2000). Turnout geometry optimization with dynamic simulation of track and vehicle, VAE AG

Received(December 5, 2012), Revised(December 11, 2012), Accepted(December 18, 2012) 